\title{
Left ventricular diastolic dysfunction in type 2 diabetes mellitus patient without cardiovascular disease: the association with microalbuminuria
}

\author{
Idrus Alwi ${ }^{*}$, S. Harun ${ }^{*}$, Soehardjono $^{\S}$, Nugroho $^{f}$, Sarwono Waspadji $^{\#}$ A. Muin Rahman ${ }^{*}$, Dasnan Ismail
}

\begin{abstract}
Abstrak
Pada 28 kasus diabetes melitus ( DM) tipe 2 tanpa kelainan kardiovaskular yang diperiksa di Bagian Metabolik Endokrin, Fakultas Kedokteran Universitas Indonesia/Rumah Sakit Umum Pusat Nasional Dr Cipto Mangunkusumo, Jakarta, mulai Oktober 2001 sampai Desember 2001, dilakukan pemeriksaan ekokardiografi untuk melihat fungsi diastolik ventrikel kiri dan dilakukan pemeriksaan urin mikroalbuminuria. Disfungsi diastolik ditemukan pada 73,7 \% pasien DM tipe 2 tanpa mikroalbuminuria dan 66,7\% pada DM tipe 2 dengan mikroalbuminuria. Tidak terdapat hubungan bermakna kejadian disfungsi diastolik pada kelompok DM tipe 2 dengan mikroalbuminuria maupun DM tipe 2 tanpa mikroalbuminuria. (Med J Indones 2005; 14: 169-72)
\end{abstract}

\begin{abstract}
Twenty-eight cases of type 2 diabetes mellitus (DM) without any cardiovascular disease were recruited from the Department of Metabolic-Endocrine, Faculty of Medicine, University of Indonesia / Dr. Cipto Mangunkusumo General Hospital, Jakarta. Recruitment of the study began in October 2001 and was completed by December 2001. Participants were examined for echocardiography and microalbuminuria urinary examination. Diastolic dysfunction was found in $73.7 \%$ of type 2 diabetic patients without microalbuminuria and $66.7 \%$ in type 2 diabetic patients with microalbuminuria. Neither type 2 diabetic groups with nor without microalbuminuria indicated any significant association to the occurrence of diastolic dysfunction. (Med J Indones 2005; 14: 169-72)
\end{abstract}

Keywords: microalbuminuria, diastolic dysfunction, type 2 diabetes mellitus

An experimental, clinical, epidemiological and pathological studies demonstrated that diabetes mellitus patients have structural and functional alteration of heart, which were independent against hypertension and coronary artery disease, which support diabetic cardiomyopathy. ${ }^{1}$

Left ventricular diastolic dysfunction may represent the early stage of diabetic cardiomyopathy. ${ }^{2}$ This emphasized

\footnotetext{
*Division of Cardiology Department of Internal Medicine, Faculty of Medicine University of Indonesia / Dr. Cipto Mangunkusumo General Hospital, Jakarta, Indonesia

${ }^{f}$ Department of Internal Medicine, Faculty of Medicine University of Indonesia / Dr. Cipto Mangunkusumo General Hospital, Jakarta, Indonesia

$\S$ Division of Nephrology Department of Internal Medicine, Faculty of Medicine University of Indonesia / Dr. Cipto Mangunkusumo General Hospital, Jakarta, Indonesia

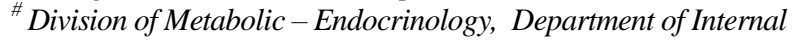
Medicine, Faculty of Medicine University of Indonesia / Dr. Cipto Mangunkusumo General Hospital, Jakarta, Indonesia
}

about the importance of early diagnosis of diastolic ventricular function in diabetic patients.

Poirier et $\mathrm{al}^{3}$ have reported that the prevalence of diastolic dysfunction in type 2 diabetes mellitus malepatients with well-controlled blood glucose level was $60 \%$. Nugroho et $\mathrm{al}^{4}$ reported the occurrence of diastolic dysfunction in type 2 diabetes mellitus patients without any cardiovascular disease in Dr. Cipto Mangunkusumo Hospital was $73.3 \%$.

The epidemiological evidence have indicated that albuminuria may predict cardiovascular morbidity and mortality in individuals with type 2 diabetes mellitus independent of conventional cardiovascular risk factors. ${ }^{5-8}$ Although the mechanism of the association of albuminuria with cardiac events is not clear, it is possible that the vascular damages that lead to renal dysfunction may also be present in the vasculature of the heart, and consequently contribute to cardiac dysfunction. ${ }^{9-10}$ 
Liu et $\mathrm{al}^{11}$ reported the association of albuminuria with systolic and diastolic left ventricular dysfunction in type 2 diabetes mellitus in American Indian population with high prevalence of obesity and hypertension, hence they were specified ethnic-group.

The association of microalbuminuria with left ventricular diastolic dysfunction in Indonesia has not been reported. Differ from the study of Liu et al, ${ }^{11}$ this study was a cross sectional study, which observed the association between microalbuminuria and left ventricular diastolic dysfunction in type 2 diabetes mellitus patients. Patients with any cardiovascular diseases such as hypertension, arrhythmia, coronary artery disease, valvular heart disease, left ventricular hypertrophy, and congestive heart failure were excluded from this study. Likewise the parameter of diastolic function assessment was not only based on mitral valve (MV) parameter but also pulmonary venous recording $(\mathrm{PV})$ in order to distinguish the normal and the pseudo-normal diastolic dysfunction.

\section{METHODS}

This was a cross-sectional study at Metabolic Endocrine and Cardiology Clinic, Dr. Cipto Mangunkusumo Hospital. The study began in October 2001 and was completed by December 2001. The diagnosis of type 2 Diabetes Mellitus was established base on WHO criteria / National Consensus on Management of Diabetes Mellitus 1998. ${ }^{12}$

Clinical history, physical examination, ECG and Treadmill exercise test had been done in order to exclude other coronary or heart disease. Albuminuria was measured by collecting urine specimen in the morning using the technique of nephelometry. Microalbuminuria was defined as a ratio of albumin / creatinine > 30 and < $300 \mathrm{mg}$ albumin / $\mathrm{g}$ creatinine. Macroalbuminuria was defined as a ratio of urinary albumin / creatinine $>300 \mathrm{mg} / \mathrm{g}$.

The echocardiography examination was conducted by using the instrument of Apogee CX 200. The examination was conducted on left lateral decubitus position by using mechanical transducer of 2.5-3 MHZ. All recordings and measurements were obtained by the same observer according too the recommendations of the American Society of Echocardiography. ${ }^{13}$ The measurement of transmitral blood flow velocity and Doppler pulse sample volume were put on the middle of mitral annulus. In addition, transmitral Doppler flow pattern : peak $\mathrm{E}$ velocity in centimeters per second (peak early transmitral filling velocity during early diastole), peak A velocity in centimeters per second (peak transmitral atrial filling velocity during late diastole). Then, the E/A ratio and deceleration time in milliseconds (time elapsed between peak $\mathrm{E}$ velocity and the point where the extrapolation of the deceleration slope of the $\mathrm{E}$ velocity crosses the zero baseline $)^{14}$ were calculated. Pulmonary venous flow recordings were obtained from the four chamber view directed at the right upper pulmonary vein where sample volume was obtained $1-2 \mathrm{~cm}$ into the pulmonary vein. The following measurements were carried out : peak $S$ wave velocity in centimeters per second (peak systolic pulmonary venous inflow velocity during ventricular systole), peak D velocity in centimeters per second (peak diastolic pulmonary venous inflow velocity during early phase of atrial diastole), and peak A wave velocity in centimeters persecond (peak reversed systolic wave during atrial contraction).

\section{Statistical analysis}

Data analysis was by SPSS Software. Data was expressed as mean \pm SD. The diastolic dysfunction of both groups, the microalbuminuria and non-microalbuminuria, were compared by chi square test.

\section{RESULT}

\section{Clinical Characteristics}

Table 1. General Characteristic

\begin{tabular}{lccc}
\hline & $\begin{array}{c}\text { No Albuminuria } \\
(\mathrm{n}=19)\end{array}$ & $\begin{array}{c}\text { Microalbuminuria } \\
(\mathrm{n}=9)\end{array}$ & $\mathrm{P}$ \\
\hline Age (yrs) & $52.21 \pm 6.56$ & $51.11 \pm 6.92$ & 0.824 \\
$\begin{array}{c}\text { Duration of DM } \\
\text { (yrs) }\end{array}$ & $7.84 \pm 4.92$ & $7.11 \pm 3.02$ & 0.633 \\
$\begin{array}{c}\text { Body Mass Index } \\
\text { (BMI) }\end{array}$ & $25.02 \pm 3.51$ & $24.83 \pm 2.36$ & 0.887 \\
$\begin{array}{c}\text { Systolic blood } \\
\text { pressure (mmHg) }\end{array}$ & $119.47 \pm 8.48$ & $123.33 \pm 8.66$ & 0.25 \\
$\begin{array}{c}\text { Diastolic blood } \\
\text { pressure (mmHg) }\end{array}$ & $77.89 \pm 4.19$ & $77.78 \pm 4.41$ & 0.945 \\
HbA1c & $8.88 \pm 1.88$ & $7.61 \pm 1.05$ & 0.041 \\
\hline
\end{tabular}

Type 2 diabetes mellitus patients with microalbuminuria and no-microalbuminuria had no significant difference for age, sex, disease duration, pulse rate, diastolic blood pressure and body mass index. Microalbuminuria groups had higher mean score on the 
systolic blood pressure than the non-albuminuria groups, but this difference was not statistically significant. HbA1C level was lower in microalbuminuria groups than the no-microalbuminuria group.

Table 2. Left Ventricular Diastolic Filling

\begin{tabular}{cccc}
\hline & $\begin{array}{c}\text { Type 2 Diabetes } \\
\text { Mellitus Without } \\
\text { microalbuminuria } \\
(\mathrm{n}=19)\end{array}$ & $\begin{array}{c}\text { Type 2 Diabetes } \\
\text { Mellitus with } \\
\text { microalbuminuria } \\
(\mathrm{n}=9)\end{array}$ & $\mathrm{P}$ \\
\hline $\begin{array}{c}\text { E velocity } \\
(\mathrm{cm} / \mathrm{s})\end{array}$ & $70.89 \pm 13.92$ & $76.78 \pm 8.76$ & 0.258 \\
A velocity & $80.53 \pm 18.02$ & $82.44 \pm 10.49$ & 0.771 \\
$\quad$ (cm/s) & $0.92 \pm 0.28$ & $0.95 \pm 0.21$ & 0.46 \\
$\begin{array}{c}\text { Ratio E/A } \\
\text { Deceleration } \\
\text { time (DT) }\end{array}$ & $202.63 \pm 47.82$ & $225.56 \pm 49.02$ & 0.25 \\
Isovolumic & $123.16 \pm 18.87$ & $117.78 \pm 16.41$ & 0.599 \\
relaxation \\
time (IVRT)
\end{tabular}

Mitral E velocity and mitral A velocity in microalbuminuria and no-microalbuminuria had no statistical difference. Likewise, mitral isovolumetric relaxation time and mitral $\mathrm{A}$ wave duration were not different for both of groups. There was no significant difference for diastolic dysfunction for both of group.

\section{DISCUSSION}

The study of diastolic function in type 2 Diabetes Mellitus patients of Indonesian was reported by Nugroho et al. ${ }^{4}$ The study found a high prevalence of diastolic dysfunction i.e. 73.3\%. This data was similar to overseas study, which had been reported by Poirier et $\mathrm{al}^{3}$, i.e. $60 \%$.

The association between albuminuria and left ventricular systolic and diastolic dysfunction in type 2 diabetes mellitus patients was first reported by Liu et al. ${ }^{11}$ They found that albuminuria was independently associated with systolic and diastolic dysfunction in type 2 diabetes mellitus. This may explain part of the association between albuminuria and enhancement of cardiovascular disease in diabetes mellitus patients.

This study was the first study in Indonesia, which reported the association between microalbuminuria and left ventricular diastolic dysfunction. Apart from Liu et al study, ${ }^{11}$ in this study, patients with hypertension and coronary heart disease (CHD) were excluded.

In the study of Liu et $\mathrm{al}^{12}$, there was a greater proportion of hypertension patients in albuminuria group compared to the non-albuminuria group. Likewise, there was significant greater proportion of CHD patient in macroalbuminuria group compared to the nonalbuminuria group. Hence, by diastolic dysfunction in albuminuria group, it might be affected by hypertension, which probably act as confounder. Excluding the CHD patient also did statistical analysis study.

Microalbuminuria has been proposed to represent a marker of a generalized vascular dysfunction, ${ }^{15}$ Some studies indicated microalbuminuria is associated with cardiovascular disease in diabetic and non diabetic patients. ${ }^{16,17}$ The study of Liu et $\mathrm{al}^{11}$ revealed an association of microalbuminuria with cardiomyopathy in type 2 diabetes mellitus.

In this study there was no significant association between microalbuminuria and diastolic dysfunction. May be microalbuminuria has minor role on cardiomyopathy, which has become the basic of diastolic dysfunction in diabetes mellitus other than coronary artery disease and hypertension with left ventricular hypertrophy. Other factor that may explain difference of the study of Liu et al, ${ }^{11}$ was a relativesmall sample number. Other cause was exclusion of hypertension patients who could affect diastolic function from the study.

\section{CONCLUSION}

There was no significant difference on diastolic dysfunction in type 2 diabetes mellitus patients with microalbuminuria compared to the non-microalbuminuria patients. We need larger sample number with prospective (cohort) design in order to observe the causative correlation of microalbuminuria and diastolic dysfunction. 


\section{REFERENCES}

1. Fang ZY, Prins JB, Marwick TH. Diabetic cardiomyopathy : evidence, mechanisms, and therapeutic implications. Endocrine Reviews 2004;25(4):543-67.

2. Raev DC. Which left ventricular function is impaired earlier in the evolution of diabetic cardyomyopathy? An echocardiographic study of young type 1 diabetic patients. Diabetes Care 1994;17:633-9.

3. Poirier P, Bogaty P, Garneau C, Marois L, Dumesnil JG. Diastolic dysfunction in normotensive men with wellcontrolled type 2 diabetes. Importance of maneuvers in echocardiographic screening for preclinical diabetic cardiomyopathy. Diabetes Care 2001;24:5-10.

4. Nugroho BS, Rachman AM, Suryadipradja RM, Waspadji S. Diastolic dysfunction in type 2 diabetes mellitus without cardiovascular abnormality. Indones $\mathbf{J}$ Intern Med 2003;35:131-5.

5. Morgensen CE. Microalbuminuria predicts clinical proteinuria and early mortality in maturity onset diabetes. N Engl J Med 1984;310:356-60.

6. Jarret RJ, Viberti GC, Argyropoulos A, et al. Microalbuminuria predicts mortality in non-insulin-dependent diabetes. Diabet Med 1984;1:17-9.

7. Schmitz A, Vaeth M. Microalbuminuria. A major risk factor in non-insulin-dependent diabetes. Diabet Med 1988;5:126-34.

8. Mattock MB, Morrish NJ, Verbti G, et al. Prospective study of microalbuminuria as predictor of mortality in NIDDM. Diabetes 1992;42:736-41.
9. de Zeeuw D, Remuzzi G, Parving HH, et al. Albuminuria, a therapeutic target for cardiovascular protection in type 2 diabetic patients with nephropaty. Circulation 2004;110:921-7.

10. Weir MR. Microalbuminuria in type 2 diabetics : an important, overlooked cardiovascular risk factor. J Clin Hypertens 2004;6(3):134-43.

11. Liu JE, Robbins DC, Palmieri V, et al. Association of albuminuria with systolic and diastolic left ventricular dysfunction in type 2 diabetes. The Strong Heart Study. J Am Coll Cardiol 2003;41:2022-8.

12. Sahn DJ, DeMaria A, Kisslo J, et al. The Committee on M-mode Standardization of the American Society of Echocardiography : recommendations regarding quantitation in M-mode echocardiography. Results of a survey of echocardiographic measurements. Circulation 1978; 58:1072-83.

13. Oh JK, Appleton CP, Hatle LK, Nishimura RA, Seward JB, Tajik JA. The noninvasive assessment of left ventricular diastolic function with two dimensional and Doppler echocardiography. J Am Soc Echocardiogr 1997;10:246-70.

14. Konsensus Diabetes Melitus di Indonesia. Perkeni. 1998

15. Deckert T, Feldt-Rasmussen B, Borch-Johnsen K, et al. Albuminuria reflects widespread vascular damage- the Steno Hypothesis. Diabetologia 1989;32:219-26.

16. Yudkin JS, Forrest RD, Jackson CA. Microalbuminuria as predictor of vascular disease in non-diabetic subjects. Islington diabetes Survey. Lancet 1988:I:530-3.

17. Roest M, Banga JD, Janssen WMT, et al. Excessive urinary albumin levels are associated with future cardiovascular mortality in postmenopausal women. Circulation 2001;103:3057-61. 
